\title{
Dell Computers: Competing Toward Decline?
}

James Grinnell, Merrimack College, USA

Cristina Muise, Merrimack College, USA

\begin{abstract}
From its modest beginnings in a college student's dorm room 25 years ago, Dell Computers has enjoyed unprecedented growth and success. Throughout its history, the company has received countless accolades for its hyper-efficient production system. Notwithstanding this distinctive competitive advantage, Dell Computers has experienced significant problems during the past few years. Will the next few years be a time of rebirth for the once high-flying company, or is this the "beginning of the end" for Dell Computers?
\end{abstract}

Keywords: organizational turnaround, competitive advantage, and organizational decline

\section{INTRODUCTION}

C n 1984, Apple Computer and IBM dominated the personal computer market. At that time, Dell Computers was a ground-floor operation headquartered in a dormitory room at the University of Texas Austin. By 2009, Apple Computer accounted for less than five percent of PC sales. (The company is rapidly transforming from a computer company to a digital music hardware and content provider, making more profit from its phenomenally successful iPod and iTunes than from computers.) IBM's stature in the PC industry has likewise waned. In 2005, the company abandoned the personal computer market altogether, selling its operations to a Chinese company. Although Dell's future looks cloudy as of 2009, no one can argue that the company's climb to success in the computer industry has been nothing short of phenomenal.

Michael Dell has always been an entrepreneurial individual. When he was 12 , he and a friend capitalized on their interest in stamp collecting by starting a stamp auction business. The two partners had experience buying from local stamp auctioneers, who acted as the middlemen between seller and buyer. Dell advertised his 12-page catalogue — which he produced himself on a clunky old typewriter — in a stamp collectors trade magazine. To Dell's amazement, the business produced a $\$ 2,000$ profit!

Four years later, Michael expanded his business horizons, this time selling subscriptions to The Houston Post. Initially cold calling the list of phone numbers provided by the paper, Michael soon realized that two groups seemed most interested in subscriptions - newlyweds and new arrivals to the Houston area. Dell struck gold after he tracked down newly filed marriage certificates (which was public information in Texas) and finagled contact information from a number of local mortgage companies. Dell recounts his newspaper success in his biography Direct from Dell: "One day, my history and economics teacher assigned us a project for which we had to file our tax return. Based on what I had made selling newspaper subscriptions, my income was about $\$ 18,000$ that year. At first my teacher corrected me, assuming I had missed the decimal place. When she realized I hadn't, she became even more dismayed. To her surprise, I had made more money that year than she had." At the ripe age of sixteen, Michael Dell's entrepreneurial proclivities were becoming increasingly obvious.

In 1984, Michael Dell enrolled in the University of Texas Austin as a pre-med student. Dell spent far more time hawking computer components out of his dorm room than he did studying. Dell invested $\$ 1,000$ to incorporate his business and he was on his way. (Interestingly, Compaq Computers was founded two years prior, with initial seed capital exceeding $\$ 100$ million!) Within months, Michael Dell was selling an astonishing $\$ 80,000$ worth of computer equipment monthly. By the end of his first year, Dell left the university — sans degree-as the president of 
a fledgling computer business. From his experience selling stamps as a twelve year old, Michael Dell knew the benefits of cutting out the middlemen. The benefits were so plain to see that Dell questioned why no one thought of selling computers direct before he did. Fortunately for Dell, no one had.

\section{THE RISE OF DELL COMPUTERS (1984-2004)²}

The production process at Dell is a "pull" system in which computers are made to order. The production process begins when customers place orders via phone or internet. Dell's flexible manufacturing process enables the company to produce and ship each customized product within four to eight hours after receiving an order. The direct-to-consumer approach is an integral part of Dell's super-efficient production system. The true benefit is that it enables Dell to gain tremendous efficiencies on the backward end of the supply chain. Possibly no company has mastered just-in-time inventory better than Dell Computers.

At Dell's state-of-the-art Morton L. Topfer Manufacturing Center (referred to as TMC), suppliers locate their operations in close proximity to the factory. Dell instantaneously notifies suppliers of needed parts as orders come in from customers. Suppliers have 90 minutes to ship the parts to the TMC. Trucks entering the delivery area systematically park at one of the 110 delivery bays. Forklift operators pluck only those pallets of parts needed for work currently in process. Once the forklift crosses a white line on the floor of the loading dock, scanners register the parts and the inventory shifts from the supplier's books to Dell's. The remaining parts on the truck remain the supplier's inventory until offloaded.

Dell supports its JIT system through sophisticated forecasting techniques. The company is so obsessive about measuring everything that industry insiders often note that the company has never met a metric that it did not like. All that data gets poked and prodded by company analysts to develop highly accurate demand forecast models. (The company shares these forecasts with suppliers.) Dell can accurately forecast $75 \%$ of the time. While far from perfect, the success rate enables Dell to keep an already efficient inventory system humming along relatively smoothly. In instances where forecasts prove inaccurate, Dell uses a supply-chain strategy called demand shaping to shift purchase patterns to more readily available components. For instance, if the company is having difficulty getting $2.8 \mathrm{GHz}$ Pentium 4 processors, it will offer a special on an upgrade. Michael Dell elaborates on how the company uses demand shaping: "Information is our most important management tool... If the folks in our consumer business notice it's 10 am and they're not getting enough phone calls, they know they have to do something: run a promotion on the Web, starting at 10:15, or change their pricing or run more ads. They can't wait until 30 days after the end of the quarter to figure it out." ${ }^{3}$

Efficiency is furthered by Dell's scrupulous focus on what happens within the walls of its production facilities. Prior to 1997, Dell used a traditional mass assembly model to manufacture its computers. Mass assembly techniques typically work best when there are few deviations in the production process. Since Dell essentially builds each computer to meet the needs and demands of individual customers, the features of the final product vary widely. Clearly, this is not an optimal setting for mass assembly. Because of the difficulty in accommodating customized products within a traditional mass production system, Dell implemented a cellular manufacturing model in 1997. With the cellular manufacturing system, teams of employees work collaboratively to assemble computers according to customer specifications. (In mass assembly settings workers perform narrow, repetitive tasks.)

In 2000, Dell implemented a Six Sigma program, with a goal of eliminating $\$ 1.5$ billion in expenses. Achieving the Six Sigma standard involves adhering to a rigorous, data-driven improvement process, which has as an ultimate goal the reduction of defects to no more than 3.4 defects per million observations. (General Electric, one of the most avid adherents to Six Sigma, saved $\$ 10$ billion during the first five years of its program.) Some of the recommendations made under Dell's Six Sigma program are relatively simple, such as printing parts lists on plain as opposed to colored paper (net savings of $\$ 23,000$ yearly). Other changes return dramatic savings. For instance, the program highlighted the inefficiencies of Dell's accounts payable system (the new system resulted in estimated annual savings of $\$ 2.4$ million $^{4}$ ).

Dell hasn't always been so efficient. In the early 1990s, the company began to question the long-term viability of the direct-sales model. In the pursuit of expanded sales, Dell started offering PCs through the retail channel. The move had its intended effect, goosing sales to $\$ 2.8$ billion in 1994 . The only problem was that the 
company faced the demon that plagues other computer manufacturers: excess inventory. Dell's inventory swelled to nearly a month's worth of computer equipment. The company suffered a staggering $\$ 36$ million loss that year. This experience reinforced the company's disdain for inventory. Kevin Rollins (CEO of Dell from 2004-2007) likened inventory to perishable food products: "The longer you keep it the faster it deteriorates-you can literally see the stuff rot. Because of the short product lifecycles, computer components depreciate anywhere from a half to a full point a week. Cutting inventory is not just a nice thing to do. It's a financial imperative." ${ }^{5}$ Michael Dell echoed a similar sentiment:

The typical case in our industry is the factory building 10,000 units a day, day in and day out. First the machines stack up in the warehouse, and then they stack up in the channel. And all of a sudden, the guy at the end of the chain hollers, "Whoa, hey, we've got too many of these. Everybody stop!" And the order to stop flows back through the chain until it reaches every component supplier. It's literally stop and start, because if you have a 90day lag between the point of demand and the point of supply, you're going to have a lot of inefficiency in the process. And the more inventory and time you have, the more variability, and the more problems. ${ }^{6}$

Dell's hyper-efficiency relies on more than a streamlined and efficient production system - the company's structure reflects the original entrepreneurial emphasis on speed and leanness. Even as a multi-billion dollar corporation, Dell maintains a flat organizational structure that promotes decentralized decision-making. A 2004 article in Strategy \& Business describes the company's structure as such:

Dell is a prototypical flat organization. From the factory floor to corporate communications, decisions are made quickly and without the burden of superfluous hierarchy. If a supervisor on the factory floor sees a way to reduce component inventories, he simply does it without going up the chain of command for approval. Dell's internal communications have stayed efficient, so that decisions that don't require the attention of senior management get made without them. ${ }^{7}$

Beyond being able to turn on a dime to meet market demand shifts, Dell's production model has tremendous implications for cash flow. When a customer places an order with Dell, the company instantaneously receives cash (typically via credit card payment). In turn, Dell's suppliers do not receive payment for 30-36 days. That's like getting a zero percent interest rate loan from suppliers! In contrast, computer manufacturers such as H-P using traditional distribution channels have to wait for retailers and distributors to pay their bills. During the heyday of the direct-to-consumer model, Dell Computers was a cash-generating machine.

\section{THE TIDE BEGINS TO TURN: THE KEVIN ROLLINS ERA (2004-2007)}

In 2004 when Michael Dell stepped down as CEO (he retained the position of Chairman of the Board), Dell Computers was the dominant player in the computer industry. No other company could rival the breathtaking efficiency of Dell's production system. The company's closet rival H-P was still struggling to find its footing after the mega-merger between HP and Compaq. (At that time, Dell sold more PCs than the combined sales of the next four largest computers sellers.) Michael Dell's replacement-Kevin Rollins-could not have inherited a more enviable situation. Nevertheless, Rollins' tenure as CEO of Dell would last a mere three years, and the company he would leave behind would be vastly different from the one he inherited.

Kevin Rollins joined Dell in 1996, first as Senior VP for Corporate Strategy, and then ultimately becoming President of North American Operations and COO. Rollins' credentials were impeccable. Prior to joining Dell, he was a partner at Bain \& Company (a prestigious management consulting firm), where he specialized in strategic management for high-tech firms. In fact, it was because of his expertise that Dell Computers retained the services of Bain \& Company in 1993 to help the company develop strategies for improving its direct-to-consumer approach. It is widely acknowledged within the company that Rollins was the one who brought the metric-centric company to a whole new level of rigorous measurement. In so doing, his recommendations helped catapult Dell Computers to the top of the computer industry. Thus, it was a no brainer for Michael Dell to bring Rollins onboard as a full-time employee of Dell in 1996. 
After assuming the CEO position, Rollins quickly determined that for all the company's success, something just wasn't right. While all financial indicators indicated that the company was performing admirably well, Rollins became concerned that Dell was losing its soul. As he explained in a 2004 interview: "I realized that we had created a culture of stock price, a culture of financial performance, and a culture of 'what's in it for me?' throughout the employee base. There had to be something more in this institution that we loved and enjoyed more than just making

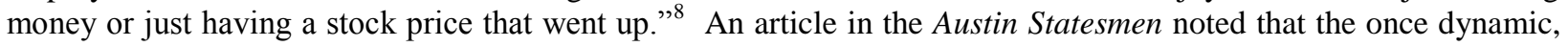
entrepreneurial culture was beginning to ossify and the motivation of the workforce waning:

In interviews with more than two dozen current and recently departed employees, two common themes emerge:

1. Many who joined the company in the go-go days of the 1990s said that Dell has become top-heavy and bureaucratic, not the exciting, hard-charging place it was. It has cracked the top 25 on the Fortune 500 list, and it's twice the size it was in 2000. But with that, some employees said, has come a management style that's too constraining.

2. Others lamented that there's little financial incentive to stay. Nine out of 10 Dell stock options - once the key to enormous wealth - would cost more to exercise than the shares are worth. For many workers, the last in-the-money options, issued not long after the Sept. 11 attacks, recently became worthless. ${ }^{9}$

Rollins characterized the state of Dell as in transition, from adolescence to maturity: "I think we've moved from teen-aged to adulthood right now, early adulthood. We just don't want to get to old age. We want to stay at maturity and keep going." ${ }^{10}$ To Rollins, the most serious threat to the company's future was the company itself. Dell Computers needed to reconsider its core values if it was to maintain its leadership role in the computer industry. The company Kevin Rollins inherited had only one core value - to win. Dell's culture emphasized the fanatical pursuit of performance improvement, obsessive emphasis on cost reduction, and an unrelenting quest for speed, the intent of all was to dominate the marketplace.

Feedback from the company's employee survey process (known as the Tell Dell surveys) suggested that employees desired more opportunities for career development as well as a better work-life balance. The surveys also indicated that the company was rewarding too many managers who made their numbers, but lacked communications skills or the appreciation for collaborative managerial practices. Overall, the company had developed a sink-or-swim philosophy. The negative aspects of the culture identified by the Tell Dell Surveys were confirmed in a cultural audit performed by a consulting firm.

Restoring balance to the company meant that the core values of Dell had to emphasize more than winning. In response to this feedback, Rollins and Dell developed a new statement of company values named The Soul of Dell (Table 1). The Soul of Dell (summarized in the box below) emphasized five primary priorities: (a) providing a superior customer experience, (b) emphasizing employee teamwork and development, (c) maintaining direct and open communications with employees, (d) acting as a responsible corporate citizen, and (e) having a passion for winning.

The loss of soul—while important - may have only been the tip of the iceberg. By 2006, the company was beginning to stumble. In that year, H-P overtook Dell as the world's largest PC producer (as of August $2009 \mathrm{H}-\mathrm{P}$ had a $19.8 \%$ market share compared to $13.7 \%$ for Dell) and Dell's growth slipped below the industry growth rate for the first time in the company's history. The swift change in Dell's fortunes was the result of three main factors: (a) customer service problems resulting from outsourcing customer support; (b) product quality problems related to defective laptop batteries; and (c) the company's faulty response to declining desktop sales. 
Table 1: Statement of Company Values

\begin{abstract}
The Soul Of Dell
Many people are familiar with Dell's customer-focused direct business model, and the company's success in creating leading value for customers and investors. Less well known is the unique environment forged by Michael Dell and the people of Dell since the company's founding in 1984.
\end{abstract}

We characterize that environment in a statement of corporate philosophy called the "Soul of Dell." It defines the kind of company we are and aspire to become, serves as a guide for our actions around the world, and ultimately forms the basis of our "winning culture."

Below are the core elements of the Soul of Dell:

Customers: We believe in creating loyal customers by providing a superior experience at a great value. We are committed to direct relationships, providing the best products and services based on standards-based technology, and outperforming the competition with value and a superior customer experience.

The Dell Team: We believe our continued success lies in teamwork and the opportunity each team member has to learn, develop and grow. We are committed to being a meritocracy, and to developing, retaining and attracting the best people, reflective of our worldwide marketplace.

Direct Relationships: We believe in being direct in all we do. We are committed to behaving ethically; responding to customer needs in a timely and reasonable manner; fostering open communications and building effective relationships with customers, partners, suppliers and each other; and operating without inefficient hierarchy and bureaucracy.

Global Citizenship: We believe in participating responsibly in the global marketplace. We are committed to understanding and respecting the laws, values and cultures wherever we do business; profitably growing in all markets; promoting a healthy business climate globally; and contributing positively in every community we call home, both personally and organizationally.

Winning: We have a passion for winning in everything we do. We are committed to operational excellence, superior customer experience, leading in the global markets we serve, being known as a great company and great place to work, and providing superior shareholder value over time.

Source: http://www.dell.com/content/topics/global.aspx/about_dell/values/supp_citizen/soul?c=us\&l=en\&s=corp\#soul

In part, Dell's decline was the result of some significant customer service setbacks. During the tech-bust in 2001, Dell like all computer companies scrambled to find ways to reduce costs. The company saw an opportunity to save significant money by outsourcing its customer service to India. (In a related decision, the company also shortened its warrantees from three years to three months.) At the time, few could question this decision because India was fast becoming a Mecca for outsourcing telemarketing. However, from the beginning, outsourcing created problems for the company. A Forbes article describes the problems created by outsourcing technical and customer support to India: "Dell was among the earliest computer companies to route customer service and technical support calls to India. Dell set up its first center in Bangalore in 2001 ... Language and cultural rifts between disgruntled U.S. customers and Dell's bright but unseasoned Indian support staff fueled the flames. U.S. customers say they got frustrated when Dell employees fielding calls seemed unwilling to depart from a script." ${ }^{\prime 1}$ The company quickly realized a backlash from its outsourced support functions, particularly from commercial customers but also amongst its consumer market. At a time when computers were rapidly becoming commodity products, customers viewed after-sales support as a key determinant in how they evaluated computers. While the intent of outsourcing was to reduce the company's cost structure - thereby enabling it to lower its prices to consumers - the result was a significant public relations fiasco. Outsourcing created tremendous reverberations amongst existing and potential customers. Rollins ultimately conceded that this short-term cost saving came at the expense of long-term success. As he stated in a 2006 interview: "We have to change our perspective and we have to do things that drive long-term success, not short-term success. I think that's a bit of a change in perspective, and it's just maturing of the management." ${ }^{12}$ Because of the substantial loss of goodwill, Dell had to plow $\$ 100$ million dollars into new hiring and training to enhance sales and support. 
In addition to the company's customer service problems, Dell's image was further tarnished by quality problems and poor product design. In 2006, the company ordered a massive recall of 4.1 million laptop batteries after a video circulating on the internet showed a Dell laptop burst into flames during a conference in Japan. Stories of laptop combustions spread (like wildfire) across the internet. In one such incidence, a house in Biddeford Maine burned to the ground. The State Fire Marshall, who attributed the fire to a Dell Inspirion laptop, stated the following: "That was the only thing we had in terms of a heat source. The couch was totally burned out, and the laptop was still sitting on what remained of the sofa." 13 While the cause of the laptop fires was eventually attributed to the lithium-ion battery produced by Sony (and in fact affected other laptop manufacturers such as Apple and $\mathrm{H}$ P), Dell became a scapegoat in the blogosphere.

Possibly the most significant cause of Dell's performance slippage was the company's lackluster response to the shift from desktop to laptop computers. Simply put, Dell was flat-footed in recognizing that customers were abandoning desktops for laptops in droves. Within a mere three year period, demand for desktops evaporated precipitously. This was particularly problematic for Dell as its ultra-efficient factories were set up for desktop as opposed to laptop production. In essence, the company found itself in a position of being a highly efficient producer of products customers no longer sought. In comparison, competitors such as H-P were shifting the production of their laptops to lower cost Asian contract manufacturers. A Wall Street Journal article said the following of Dell's loss of its cost advantage: “... Dell has lost its low-cost edge as its rivals shifted to using Asian factories-for-hire to build their wares. Today, many of Dell's own factories, such as the one in North Carolina that's only about three years old, can no longer compete on cost." ${ }^{14}$ Further compounding problems with Dell's product line-up was a general disregard for designing products with appeal to the consumer market. As one industry analyst put it: "Dell also failed to capture the imagination of consumers with its products, which were viewed as dull at best and ugly at worst. Rollins was excellent at supply chain and logistics but did not seem to understand the importance of industrial design." 15

While Michael Dell and Kevin Rollins had a history of working collaboratively - and thus the blame for Dell's decline should have been shared equally between the two-there was a growing perception on Wall Street that Kevin Rollins was responsible for the company's sub-par performance. As one Wall Street analyst put it: "Coincidence or otherwise, Kevin's visibility rose about the time the wheels starting coming off. At the end of the day, employees and investors can't see the two men sitting at two desks with an open wall, collaborating with each other. All they see is two eras of Dell marked with two different names at the helm."16

\section{POSTSCRIPT: THE RETURN OF MICHAEL DELL}

On January 31, 2007, Kevin Rollins' era as CEO came to an unceremonious end as Michael Dell stepped back into the CEO role. Although Dell had maintained confidence in Rollins, the mounting financial performance slump, coupled with allegations of accounting improprieties finally got the better of Rollins. One Wall Street analyst noted, "It's surprising. Rollins had the confidence of (Michael) Dell, but when you look at the numbers you can see why Dell has retaken the helm. They have been suffering from a corporate market slump, and the usual bag of tricks-leveraging the supply chain and their economies of scale- haven't worked."17

Dell Computers announced a dramatic about-face in 2008. First, the company is actively trying to unload its factories and is working with contract manufactures to manufacture its products. (The company owns factories in Texas, Tennessee, North Carolina, Florida, Ireland, India, China, Brazil, Malaysia, and Poland.) Dell's factories are still the most efficient in the world, but they are set up for manufacturing desktop computers. With laptops the company uses a cumbersome process in which laptop are partially manufactured by contract manufacturers and then shipped to Dell factories for final manufacture. This process, referred to as the "two touch" system by Dell, is significantly less efficient (and more costly) than competitors such as H-P and Apple who farm out the entire laptop production process. The second change of direction announced by the company in 2008 was that it was going to once again sell its computers in the retail channel (e.g., with Walmart and Best Buy). Whereas customers were willing to purchase desktop systems without seeing, feeling, and touching them, laptops were different. Consumers were far more hesitant to purchase these systems without first seeing them. While the company's original foray into retail sales ended under inauspicious circumstances, by 2008 Dell had little leeway in the decision to utilize traditional retail channels. 
In a press release announcing his return to the helm of the company he founded, Michael Dell said the following: "Dell has tremendous opportunities ahead of it, I am enthusiastic about Dell 2.0, which includes our plan to provide the best customer experience, build a strong global services business and ensure our products deliver the best long-term customer value." What exactly will Dell 2.0 look like? Will it succeed? Or is Dell Computers another story of a company that leveraged their capabilities to shoot to the top of their industry, only to fade as quickly because it became too enamored of itself to continue to grow and evolve? The story continues to unfold.

\section{DISCUSSION QUESTIONS}

1. Discuss the primary benefits Dell Computer derived from its just-in-time inventory system.

2. Perform a Porter's Five Forces analysis for Dell Computers. Which forces are of primary importance to Dell?

3. Dell Computers is widely admired for its competitive edge associated with efficiency. Yet, in spite of this strength, the company has experienced a precipitous decline in its competitive position. What specific factors account for this decline?

4. Kevin Rollins identified the myopic focus on winning as a primary problem for Dell Computers. In hindsight, did he make a mistake in making the "Soul of Dell" a strategic priority during his time as CEO?

5. Kevin Rollins was widely blamed for the diminishment of Dell's competitive position. Discuss whether this assignment of blame was appropriate or not. Should Michael Dell also receive commensurate blame?

6. Evaluate the company's two recent decisions to (a) sell its production facilities and outsource production and (b) distribute through traditional retail channels. Do these decisions make sense for the company?

7. The case concludes with the following questions: What exactly will Dell 2.0 look like? Will it succeed? Or is Dell Computers another story of a company that leveraged their capabilities to shoot to the top of their industry, only to fade as quickly because it became too enamored of itself to continue to grow and evolve? Discuss each of these questions.

\section{AUTHOR INFORMATION}

Dr. Grinnell's research has focused broadly on gender and leadership and the transformation of business education. He has presented his scholarship at national and international conferences and has published his work in Psychological Reports and Advanced Management Journal. Dr. Grinnell presently serves as the assistant dean of the Girard School of Business and International Commerce at Merrimack.

Dr. Muise held positions as Chief Financial Officer and Chief Operating Officer, with responsibility for strategic business planning, finance and operations of a company with global operations. She remains active in the professional sector through consulting for small to mid-size companies as well as participating in real estate investment activities. Her research has focused on the effects of corporate social responsibility on firm valuation.

\section{ENDNOTES}

${ }^{1}$ Dell, M., \& Fredman, C. (1999). Direct from Dell. HarperCollins Publishers: pp. 5-6.

${ }^{2}$ Unless otherwise noted, much of the information in this and the next section was drawn from Breen, B. (2004). Living in Dell time. Fast Company, Issue 88. Retrieved 3/20/05 from www.fastcompany.com/magazine/88/dell.html.

3 ---- (2005). Execution without excuses: An interview with Michael Dell and Kevin Rollins. Harvard Business Review, March: pg. 5

4 Arndt, M. (2002). Quality isn’t just for widgets. Business Week: July 22. Retrieved 3/28/05 from www.businessweek.com/magazine/content/02_29/b3792097.htm

${ }_{5}^{5}$ Breen, B. (2004). Living in Dell time. Fast Company, Issue 88. Retrieved 3/20/05 from www.fastcompany.com/magazine/88/dell.html

${ }^{6}$ Magretta, J. (1998). The power of virtual integration: An interview with Dell Computer's Michael Dell. Harvard Business Review, March-April: pg. 77.

${ }^{7}$ Fisher, L. (2004). "How Dell got soul.” Strategy \& Business

${ }^{8}$ Ibid.

${ }^{9}$ Zehr, D. (2006). "Dell regroups, forges ahead.” The Statesman, July 26, retrieved 8/17/2009 http://www.statesman.com/money/content/shared/money/stories/DELL 0726 COX.html 
${ }^{10}$ Ibid.

${ }^{11}$ Corcoran, E. (2004). "Dell moves outsourced jobs back to U.S. shores" Forbes, April 28, retrieved 8/17/2009

http://www.msnbc.msn.com/id/4853511/

${ }^{12}$ Zehr, D. (2006). "Dell regroups, forges ahead." The Statesman, July 26, retrieved 8/17/2009

http://www.statesman.com/money/content/shared/money/stories/DELL 0726 COX.html

${ }^{13}$ Weis, T. (2007). "Dell laptop fire destroys Maine home." Computerworld retrieved 8/17/2009

http://www.computerworld.com/s/article/9011142/Dell_laptop_fire_destroys_Maine_home

${ }^{14}$ Scheck, J. (2008). "Dell's revival strategy runs into trouble.” Wall Street Journal 11/28/2008. Retrieved 8/16/2009

${ }^{15}$ Krazit, T., \& Kanelos, M. (2007). "Michael Dell back; Rollins resigns.” CNet News, January 31, retrieved 8/17/2009 http://news.cnet.com/2100-1014_3-6155185.html

${ }^{16}$ Zehr, D. (2006). "Dell regroups, forges ahead." The Statesman, July 26, retrieved 8/17/2009

http://www.statesman.com/money/content/shared/money/stories/DELL_0726_COX.html

${ }^{17}$ Krazit, T., \& Kanelos, M. (2007). "Michael Dell back; Rollins resigns.” CNet News, January 31, retrieved 8/17/2009 http://news.cnet.com/2100-1014_3-6155185.html 